\title{
O caráter estratégico do Agente Comunitário de Saúde na APS integral
}

\author{
Angélica Ferreira Fonseca ${ }^{1,2}$, Márcia Valéria Morosini ${ }^{1}$ \\ ${ }^{1}$ Escola Politécnica de Saúde Joaquim Venâncio, Fundação Oswaldo Cruz, Rio de Janeiro, RJ, Brasil. \\ ${ }^{2}$ Correspondência para afonseca@fiocruz.br.
}

\section{SUMÁRIO EXECUTIVO}

Em diferentes países, o trabalhador comunitário de saúde se institui tendo como principal papel viabilizar o acesso a ações de saúde. Outra ideia bastante associada a esse trabalhador é a de tradutor, atuando no duplo sentido do conhecimento técnico e das práticas sanitárias para grupos específicos ou às chamadas comunidades, das quais ele mesmo é um membro; e das particularidades culturais e sociais desses mesmos grupos para os serviços e outros profissionais de saúde.

Seu trabalho é dimensionado em função das concepções de saúde, do modelo de atenção e do projeto de sistema de saúde que efetivamente se implantam em cada realidade nacional, em cada conjuntura. No Brasil, a institucionalização do agente comunitário de saúde (ACS) no âmbito do Sistema Único de Saúde (SUS) está também relacionada ao processo de ampliação do acesso e à promoção da qualidade na Atenção Primária à Saúde (APS). Transitou de um momento de maior seletividade e focalização, com ações especificamente dirigidas à melhoria de alguns indicadores de saúde e a grupos em situação de pobreza, para um momento posterior, de estruturação de um novo modelo de atenção que se articula incorporando a concepção de determinação social do processo saúde-doença e se organiza e difunde com base na Estratégia Saúde da Família (ESF).

Sua profissionalização tem características pouco consolidadas - propostas de formação e atribuições sujeitas a constantes alterações - o que contribui para que o ACS seja um marcador sensível do sentido que as políticas de saúde assumem no contexto nacional. Em outras palavras, é possível dizer que os ACS expressam mais intensa e rapidamente as tendências que se imprimem ao SUS. É portador das expectativas de um SUS democrático, participativo, integral e universal e de uma grande identificação com a população que atende. Talvez por isso, mesmo em uma conjuntura de poucos recursos e bastante sobrecarga de trabalho, como a pandemia de Covid-19, tem conseguido sustentar práticas de criatividade e resistência produzidas no cotidiano e a partir das relações que mantém no território em que vive e atua.

A partir de dados de pesquisa e depoimentos disponibilizados no contexto da pandemia, foi possível identificar ações dos ACS, tanto em resposta aos novos desafios enfrentados como para dar continuidade à atenção à saúde das pessoas assistidas. Nós as agrupamos em linhas de atuação que se apresentam no Quadro 1. São elas o acolhimento aos usuários nas unidades de saúde; vigilância comunitária ativa - monitoramento de casos, contatos e suspeitos de COVID-19; apoio à campanha de vacinação contra COVID-19; continuidade do cuidado aos usuários; e articulação e apoio aos movimentos sociais comunitários. Essas ações mobilizam saberes e modos de atuação que os ACS têm desenvolvido e abrangem atividades artísticas, comunicativas com base na educação popular, de mobilização social e integração com movimentos solidários nas comunidades (Rede APS, 2021). 
Vol. 3, n. 3, p. 210-223 | Setembro/Dezembro- 2021

ISSN 2596-3317 - DOI 10.14295/aps.v3i3.218

Fonseca, A. F.; Morosini, M. V.

\begin{tabular}{|l|l|}
\multicolumn{2}{|c}{ Quadro 1 - Linhas de ação e atividades dos ACS durante a pandemia } \\
\hline Linhas de ação & Atividades \\
\hline $\begin{array}{l}\text { Acolhimento aos usuários nas } \\
\text { unidades de saúde }\end{array}$ & $\begin{array}{l}\text { Orientação sobre os fluxos de sintomáticos respiratórios e não- } \\
\text { sintomáticos. Orientação aos usuários sobre meios de prevenção à } \\
\text { COVID-19 e sobre as formas de realização de isolamento nas } \\
\text { moradias. }\end{array}$ \\
\hline $\begin{array}{l}\text { Vigilância comunitária ativa - } \\
\text { monitoramento de casos, } \\
\text { contatos e suspeitos de } \\
\text { COVID-19 }\end{array}$ & $\begin{array}{l}\text { Visitas peridomiciliares, ligações telefônicas e trocas de mensagens } \\
\text { por aplicativo com os usuários. }\end{array}$ \\
\hline $\begin{array}{l}\text { Apoio à campanha de } \\
\text { vacinação contra COVID-19 }\end{array}$ & $\begin{array}{l}\text { Registro dos dados das pessoas vacinadas nos postos de vacinação } \\
\text { Identificação de pessoas com dificuldade de locomoção, idosos e } \\
\text { acamados e articulação de estratégias de vacinação em domicílio. }\end{array}$ \\
\cline { 2 - 3 } & $\begin{array}{l}\text { Ações para mobilização dos usuários para comparecer à 1a e 2a dose } \\
\text { vacinação - ligações telefônicas, envio de mensagens por aplicativo, } \\
\text { visitas peridomiciliares, inserções em programas das rádios } \\
\text { comunitárias etc. }\end{array}$ \\
\hline $\begin{array}{l}\text { Continuidade do cuidado aos } \\
\text { usuários }\end{array}$ & $\begin{array}{l}\text { Visitas peridomiciliares, ligações telefônicas e trocas e mensagem } \\
\text { por aplicativo com os usuários, inserções em programas de rádio } \\
\text { comunitária, elaboração de cartazes afixados nas unidades etc }\end{array}$ \\
\hline $\begin{array}{l}\text { Articulação e apoio aos } \\
\text { movimentos sociais } \\
\text { comunitários }\end{array}$ & $\begin{array}{l}\text { Participação na elaboração de ações comunitárias; } \\
\text { Identificação de sujeitos em maior risco social e definição de formas } \\
\text { de comunicação. } \\
\text { Engajamento e atuação na realização de ações de apoio social por } \\
\text { meio da distribuição de alimentos, materiais de higiene, máscaras }\end{array}$ \\
\hline
\end{tabular}

Ao mesmo tempo, sua realidade expõe as contradições de um sistema que ampliou acesso à custa da precarização do trabalho. Ainda hoje são praticadas formas de contratação sem os devidos direitos ou com direitos insuficientes, às quais se somam a sobrecarga de atividades, o significativo aumento de tarefas administrativas, o sofrimento psíquico e o desgaste físico. (Santos, Souza e Freitas, 2019; Morosini, 2018; Riquinho et al, 2018)

Num contexto de crescentes desafios trazidos pelas mudanças nas políticas voltadas para a Atenção Básica $(A B)^{1}$ e pelos efeitos da pandemia de Covid-19, faz-se especialmente importante refletir sobre as questões que se apresentam para o trabalho do ACS. Essa reflexão se coloca tanto pela importância estratégica dos ACS para a consolidação da ESF, na perspectiva da APS integral, como pela possibilidade de se compreender melhor como esses desafios se materializam na prática do trabalho na AB.

\footnotetext{
${ }^{1}$ As expressões Atenção Primária à Saúde e Atenção Básica à Saúde são utilizadas aqui de modo diferenciado. A primeira refere-se ao campo teórico-metodológico ou à nomenclatura internacional. A segunda designa o desenvolvimento da Atenção Primária à Saúde no contexto do SUS, em especial às políticas que organizam este âmbito de atenção no Brasil.
} 


\section{INTRODUÇÃO}

\section{O SUS mais próximo da população e do território: trajetória de profissionalização dos Agentes Comunitários de Saúde}

De acordo com os dados de junho de 2021 do Cadastro Nacional de Estabelecimentos de Saúde (CNES), os ACS somam 282.890 trabalhadores (Brasil, 2021). Constituem uma força de trabalho distribuída por todo o território brasileiro e predominantemente feminina, 0 que traz particularidades relacionadas às condições gerais de inserção das mulheres no trabalho - tripla jornada, postos de trabalho menos valorizados - e às características de expansão do trabalho do cuidado, em especial, menor reconhecimento social (Hirata, 2016). As informações sobre cor da pele ou raça indicam predominância da população negra (Pinto et al, 2015; Nogueira et al 2020), um marcador de desigualdade social, que, no caso de ACS, combina-se com classe e gênero.

Registros significativos da história dos agentes de saúde remetem ao ambiente dos movimentos de redemocratização do país do final dos anos 1970 e décadas de 1980 e 1990. Têm origem em experiências populares de educação e mobilização em saúde, com participação no Movimento da Reforma Sanitária Brasileira, em particular na $8^{\underline{a}}$ Conferência Nacional de Saúde. Pode-se dizer que a trajetória dessa categoria profissional remete à construção social do projeto do SUS democrático, participativo e universal, inscrito na constituição de 1988.

Sua história profissional é vinculada à $A B$, marcada por seu pertencimento ao território em que atua, expressando o propósito de aproximação entre os serviços e as pessoas que atende. Está presente em contextos variados. Em municípios nos quais a cobertura da ESF é mais elevada, sua presença se faz de modo mais abrangente. Em outros, particularmente nos grandes centros urbanos, sua atuação se dirige a territórios cuja dinâmica socioespacial é marcada por condições de vida mais precárias, situações de violência e restrito acesso a bens e serviços públicos.

Essas dinâmicas têm força importante na materialidade cotidiana do seu trabalho, implicando diferentes ritmos e cargas físicas e psíquicas. As diversas experiências vividas na proximidade do dia a dia dos territórios, associadas às particularidades da gestão gerência de serviços e de Organizações Sociais de Saúde e correlatos), influenciam os modos de exercer a função de ACS, ainda que suas atribuições sejam determinadas por diretrizes da política nacional e da gestão municipal.

Historicamente, suas atividades compreendem ações de educação em saúde realizadas principalmente no território, de produção do diagnóstico sócio sanitário, de estímulo à participação popular, acolhimento, cadastramento, registro de informações, monitoramento e acompanhamento de grupos específicos, dentre outras. Seu trabalho estrutura-se principalmente por meio de visitas domiciliares realizadas regularmente, sozinho ou acompanhado de outros profissionais. Em geral, as atividades realizadas pelos demais profissionais no território requerem a presença do ACS.

A atividade de ACS foi reconhecida como profissão em 2002 e permanece sofrendo regulamentações que abrangem a configuração do trabalho, a regularização dos vínculos, a padronização salarial e a formação profissional. Trata-se de uma categoria bastante organizada politicamente e que tem se feito representar nas diversas disputas referentes ao seu trabalho e aos seus direitos, nos planos executivo e legislativo. No cenário nacional, destaca-se a capacidade de mobilização da Confederação Nacional dos Agentes Comunitários de Saúde (CONACS) e da Federação Nacional dos Agentes de Saúde e Endemias (FENASCE). O quadro a seguir apresenta marcos desse processo. 
Quadro 2 - Principais marcos na regulação do trabalho e da formação dos ACS no SUS

\begin{tabular}{|c|c|}
\hline Ano & Fato, documento normativo ou legislação \\
\hline 1991/1992 & $\begin{array}{l}\text { Lançamento do Programa Nacional de Agentes Comunitários de Saúde (PNACS), } \\
\text { renominado Programa de Agentes Comunitários de Saúde (PACS) }\end{array}$ \\
\hline 1994 & $\begin{array}{l}\text { Lançamento do Programa Saúde da Família (PSF); mobilização para a criação de } \\
\text { uma organização nacional dos ACS. }\end{array}$ \\
\hline 1996 & $\begin{array}{l}\text { Fundação da Confederação Nacional de Agentes Comunitários de Saúde (CONACS) } \\
\text { a partir da Associação Nacional de Agentes Comunitários de Saúde }\end{array}$ \\
\hline 1997 & $\begin{array}{l}\text { Portaria no. } 1886 \text { do Gabinete do MS - aprova as normas e diretrizes do PACS e } \\
\text { do PSF e define atribuições dos ACS. }\end{array}$ \\
\hline 1999 & $\begin{array}{l}\text { Decreto no. } 3189 / 1999 \text { - fixa as diretrizes para o exercício da atividade de ACS e } \\
\text { dá outras providencias. }\end{array}$ \\
\hline 2002 & $\begin{array}{l}\text { Documento do MS: Modalidade de Contratação de Agentes Comunitários de } \\
\text { Saúde: um pacto tripartite. Orienta sobre as formas de contratação, apresentando } \\
\text { a modalidade via OSCIP (Lei 9790/99 - lei do terceiro setor) com direitos segundo } \\
\text { a CLT. }\end{array}$ \\
\hline 2002 & $\begin{array}{l}\text { Lei no. } 10507 \text { de } 10 \text { de julho de } 2002 \text { - institui a profissão de ACS e estabeleceu a } \\
\text { obrigatoriedade de realização de um curso de qualificação básica para este } \\
\text { profissional. }\end{array}$ \\
\hline 2003 & $\begin{array}{l}\text { Realização do Seminário Nacional sobre Política de Desprecarização do Trabalho } \\
\text { no SUS - ACS é um dos trabalhadores enfocados. }\end{array}$ \\
\hline 2003 & $\begin{array}{l}\text { Instaurado Procedimento Investigatório n. } 160 / 2003 \text { pelo Ministério Público do } \\
\text { Trabalho, para apurar as formas de contratação dos ACS, devido às denúncias de } \\
\text { vínculos precários. }\end{array}$ \\
\hline 2003 & $\begin{array}{l}\text { Portaria no. 2430/GM/MS - cria o Comitê Nacional Interinstitucional de } \\
\text { Desprecarização do Trabalho no SUS. }\end{array}$ \\
\hline 2004 & $\begin{array}{l}\text { Publicação do Referencial Curricular do Curso Técnico de Agente Comunitário de } \\
\text { Saúde - MS/MEC. }\end{array}$ \\
\hline 2006 & $\begin{array}{l}\text { Documento do Programa Nacional de Desprecarização do Trabalho no SUS: } \\
\text { Desprecariza SUS: perguntas \& respostas - Comitê Nacional Interinstitucional de } \\
\text { Desprecarização do Trabalho no SUS. }\end{array}$ \\
\hline 2006 & $\begin{array}{l}\text { Emenda Constitucional 51/06 - cria o processo seletivo público para os ACS e } \\
\text { agentes de endemias. }\end{array}$ \\
\hline 2006 & Medida provisória 297 - revoga a lei 10507. \\
\hline 2006 & $\begin{array}{l}\text { Lei no. } 11350 \text { de } 5 \text { de outubro de } 2006 \text { - estabelece o vínculo direto com estados } \\
\text { e municípios via CLT e a formação: inicial e continuada, mantendo o previsto na } \\
\text { Lei } 10507 .\end{array}$ \\
\hline 2014 & $\begin{array}{l}\text { Lei } 12994 / 2014 \text { - estabelece o Piso Salarial de então } \mathrm{R} \$ 1014,00 \text { e as diretrizes } \\
\text { para o Plano de Carreira dos ACS e ACE }\end{array}$ \\
\hline 2015 & Decreto 8474 - regulamenta o Piso Salarial dos ACS e ACE \\
\hline 2015 & $\begin{array}{l}\text { Nota Técnica N. } 09 \text { de } 2015 \text { da Secretaria de Políticas da Previdência Social/MPS } \\
\text { sobre o regime jurídico de trabalho e o regime previdenciário dos ACS e ACE. }\end{array}$ \\
\hline 2015 & $\begin{array}{l}\text { Publicação pela SGTES/MS do Plano de Regularização, Qualificação do Trabalho, } \\
\text { Educação e Valorização dos Agentes de Saúde (ACS/ACE) }\end{array}$ \\
\hline 2015 & $\begin{array}{l}\text { Portaria no. 243/MS - dispõe sobre o Curso Introdutório para ACS e ACE e seu } \\
\text { conteúdo. }\end{array}$ \\
\hline 2015 & $\begin{array}{l}\text { Protocolo no. } 009 / 2015 \text { da Mesa Nacional de Negociação Permanente do SUS - } \\
\text { institui as diretrizes da Agenda Nacional do Trabalho Decente para os } \\
\text { Trabalhadores do SUS. }\end{array}$ \\
\hline 2016 & $\begin{array}{l}\text { Portaria 958/2016/MS - altera o Anexo I da Portaria no } 2.488 / 2011 \text { - suprime o ACS } \\
\text { da equipe mínima da ESF, cuja presença passa a ser facultativa e intercambiável } \\
\text { com o técnico de enfermagem. }\end{array}$ \\
\hline 2016 & Revogação em 09 de junho de 2016 da Portaria 958 de maio de 2016. \\
\hline
\end{tabular}




\begin{tabular}{|l|l|}
\hline 2016 & $\begin{array}{l}\text { Projeto de Lei - PL 6437/2016 - Altera a Lei 11350, no que diz respeito as } \\
\text { atribuiçães, a formação e aos direitos dos ACS e ACE. }\end{array}$ \\
\hline 2017 & $\begin{array}{l}\text { Portaria MS/GM No 2.436, de } 21 \text { de setembro de } 2017 \text { (PNAB 2017) - aprova a } \\
\text { Política Nacional de Atenção Básica - PNAB, com vistas à revisão da regulamentação } \\
\text { de implantação e operacionalização vigentes, no âmbito do Sistema Único de Saúde } \\
\text { - SUS, estabelecendo-se as diretrizes para a organização do componente Atenção } \\
\text { Básica, na Rede de Atenção à Saúde - RAS. }\end{array}$ \\
\hline 2018 & $\begin{array}{l}\text { Lei 13595/2018 - Altera a Lei no 11.350, de 5 de outubro de 2006, para dispor sobre } \\
\text { a reformulação das atribuições, a jornada e as condições de trabalho, o grau de } \\
\text { formação profissional, os cursos de formação técnica e continuada e a indenização } \\
\text { de transporte dos profissionais Agentes Comunitários de Saúde e Agentes de } \\
\text { Combate às Endemias. (Deriva do PL 64/37, com vetos presidenciais) }\end{array}$ \\
\hline 2020 & $\begin{array}{l}\text { Portaria MS No 3.241, de 7 de dezembro de 2020 - Institui o Programa Saúde com } \\
\text { Agente, destinado à formação técnica dos Agentes Comunitários de Saúde e dos } \\
\text { Agentes de } \\
\text { Combate às Endemias. }\end{array}$ \\
\hline 2021 & $\begin{array}{l}\text { PL 1802 de 2019 - acrescenta parágrafo à Lei 11350, afirmando que ACS e ACE são } \\
\text { profissionais de saúde -aprovado em abril de 2021 na Câmara dos Deputados e } \\
\text { encaminhado ao Senado. }\end{array}$ \\
\hline 2021 & $\begin{array}{l}\text { Edital N. 1 de 28 de abril de 2021 - SGTES/MS - Chamada Pública para os estados, } \\
\text { o Distrito Federal e os municípios aderirem ao Programa Saúde com Agente. }\end{array}$ \\
\hline
\end{tabular}

Fonte: elaborado pelos autores.

\section{PANORAMA ATUAL: CAMINHOS DA POLÍTICA E DESCONSTRUÇÕES}

A chave de compreensão do que vem se colocando no cenário do trabalho do ACS e, nesse sentido, de uma face importante da APS, consiste em perceber o sinergismo entre os mecanismos de reconfiguração da APS contidos nos documentos normativos da política (Morosini, Fonseca e Baptista, 2020). A esse sinergismo intencional, somam-se repercussões da pandemia de COVID-19 sobre o processo de trabalho em saúde.

Em primeiro lugar, trata-se dos efeitos da ação combinada de mudanças no plano da política, do modelo de atenção, do financiamento e da gestão da APS promovidos pela publicação da Política Nacional de Atenção Básica (PNAB) 2017, da Carteira de Serviços da Atenção Primária em Saúde (CaSAPS), do Previne Brasil e pela criação da Agência de Desenvolvimento da Atenção Primária em Saúde (ADAPS). Trata-se, ainda, do avanço da lógica e dos interesses privatistas sobre a gestão, a organização do cuidado e a configuração das práticas na APS.
No que diz respeito aos ACS, as ações incidem sobre dois eixos principais: sua presença nas equipes e o sentido e o escopo do seu trabalho. A presença do ACS nas equipes parecia, no plano da Política, um componente intrínseco ao próprio desenvolvimento da ESF. A partir de 2016, entretanto, passa a haver indícios concretos da intenção de relativizar essa presença, com destaque para a publicação da Portaria GM/MS n. 958/16. Essa portaria alterava a composição da equipe mínima, facultando aos municípios a substituição do ACS por técnico ou auxiliar de enfermagem, mas foi revogada rapidamente em virtude da mobilização política da categoria (Morosini e Fonseca, 2017).

A PNAB 2017 (Brasil, 2017), ao deixar sem definição o número mínimo de ACS por equipe e prever equipes sem ACS, retoma a ideia do ACS como um trabalhador do qual a APS pode prescindir. Em um cenário de redução do orçamento da saúde, com o desfinanciamento acarretado pela emenda constitucional 95, a PNAB vem oferecer aos municípios novas possibilidades organizativas da AB. Na prática, essa possibilidade de contingenciamento e de exclusão dos ACS das equipes poderá ser 
utilizada pela gestão como mecanismo para operar o racionamento de recursos.

O argumento racionalizante está diretamente implicado com a pauta de austeridade econômica ultra neoliberal que amplia as restrições às políticas sociais e promove o desmonte dos direitos firmados pela Constituição Cidadã de 1988. No campo da saúde, integra-se à desarticulação da determinação social do processo saúde-doença como diretriz, até recentemente, estruturante da organização do cuidado. Essa diretriz se refletem a territorialização da atenção e na orientação comunitária, atributos que fundamentam a APS integral e balizavam o modelo da ESF, o sentido e o escopo do trabalho do ACS. Entende-se que o sentido do trabalho do ACS, seu propósito maior, está relacionado com o horizonte de conquistas que se pretende alcançar para a população por meio da atenção à saúde. $O$ escopo refere-se às atribuições e práticas que o ACS desempenha, abrangendo o trabalho prescrito e o trabalho efetivamente realizado.

Projetava-se para esse trabalhador a expectativa de uma presença constante nas comunidades, realizando um trabalho de base interpessoal, com potencial de efetuar ações educativas culturalmente situadas e promover a articulação entre movimentos sociais nos seus territórios de referência e entre instituições de outros setores. Sustentava-se principalmente no conhecimento das pessoas, das condições de vida e das relações sociais, com capacidade para a produção de informações contextualizadas e para o desenvolvimento de estratégias de cuidado mais efetivas. Sua atuação frequente no território contribui para a recomposição da presença dos serviços e dos demais profissionais no cotidiano das áreas assistidas, desenvolvendo ações importantes para a capilaridade e a continuidade da atenção. Ao longo desses anos, seu trabalho vem sendo fundamental para a consolidação das ações dos cuidados promovidos pela APS e, talvez por isso, - ACS tenha se tornado um importante vocalizador das demandas da população, contribuindo para tornar mais evidentes, por exemplo, as falhas do sistema no que diz respeito à continuidade do cuidado em outros níveis. Portanto, a sua retirada do território tende a silenciar essas demandas e naturalizar as faltas.

Dada a centralidade que a concepção de território ocupa na APS integral e na organização da ESF e do trabalho do ACS, espera-se que uma carteira de serviços que pretende orientar gestores, trabalhadores e população sobre o que deve ser oferecido na $A B$ coloque $O$ território como alicerce da organização do cuidado. Isso deveria se refletir nas atividades e ações que a compõem. Entretanto, na CaSAPS (Brasil, 2020), o que se vê fortalecido é um enfoque clínico reduzido. A territorialização se esvazia e a noção de comunidade se enfraquece, dissociando-se da participação popular, expressão ausente do texto, e colocando em risco a construção de relações entre as equipes e as pessoas das diferentes comunidades, tal como pretendida na ESF. O ACS é citado uma única vez, relacionado apenas aos cuidados com o puerpério e à previsão de visitas domiciliares (VD), principal estratégia de trabalho dos agentes no território, destinada somente a usuários restritos ao domicílio, como recémnascidos e acamados. (Morosini, Fonseca e Baptista, 2020).

Essas mudanças de perspectiva vislumbradas na PNAB e explicitadas na CaSAPS, que adota um enfoque clínico de caráter técnico e base biomédica, encontram eco na nova política de financiamento da AB. No Previne Brasil (Brasil, 2019), prevalece uma lógica individualizante, fortalecida pela extinção do PAB fixo e adoção da capitação baseada na pessoa cadastrada e no pagamento por desempenho, baseado em sete indicadores com de base clínica. A criação da Adaps demonstra uma tomada de posição mais radical e ativa do gestor federal na criação das condições normativas para ampla atuação do setor privado na AB (Giovanella et al 2019; Morosini, Fonseca e Baptista, 2020), explicitando um contrapondo à inscrição constitucional da saúde como dever do Estado. Por vias diversas, observa-se a indução de um modelo de atenção que entra em conflito com o modelo no qual o ACS ocupa uma posição relevante e desenvolve um trabalho complexo. 
As bases do trabalho do ACS que têm justificado sua presença nas equipes e orientado sua atuação perdem espaço, o que dá força aos questionamentos sobre a resolutividade de suas atribuições historicamente constituídas. Nesse processo, abre-se oportunidade para a redefinição do sentido do seu trabalho e para a descaracterização do escopo de atividades que estabelecem sua singularidade e o distinguem de outros trabalhadores da ESF.

O sentido dessas mudanças volta-se para responder às exigências de caráter resolutivo, com base em uma clínica restrita e à diretriz de racionalização de recursos, sem considerar os achados das pesquisas e as críticas do movimento organizado dos ACS que indicavam uma crescente burocratização do trabalho e a sua instrumentalização para fins de alcance de metas dos serviços e da gestão. $O$ recente acréscimo de atividades típicas da enfermagem ao conjunto de atribuições dos ACS traz um alerta para o rumo que se pretende dar ao trabalho dos agentes. No quadro 3 apresentamos uma síntese de modificações ocasionadas por essas normativas $e$ desdobramentos importantes para a APS e impacto sobre o trabalho do ACS. É preciso acompanhar essa dinâmica, indagando, por exemplo, como essas atribuições se relacionam com o trabalho educativo? Em que grau essas práticas assumem caráter substitutivo em relação aos trabalhadores de enfermagem? Lembra-se aqui que auxiliares e técnicos de enfermagem são profissionais previstos nas equipes da ESF.

$\mathrm{Na}$ intersecção presença-sentido-escopo do trabalho, desenha-se uma dupla desconstrução, que atinge tanto a APS integral como o ACS como um articulador estratégico da integralidade na interface serviço-território. Projeta-se para esse trabalhador a inserção em uma equipe com poucos ou somente um ACS, o que propicia sua retirada do cotidiano do território. Seu tempo de trabalho tende a ser destinado para a execução de tarefas vinculadas a metas clínicas de orientação tecnicista, de vigilância pontual limitada aos agravos e de atividades burocratizadas relacionadas ao registro e à produção de informações. Por tratar-se de atividades relevantes, tendem a ocultar ainda mais o prejuízo que a ESF sofre ao concentrar o trabalho dos ACS em torno delas.

Em um contexto de maior sobrecarga do que a já experimentada, é possível que ocorra seu afastamento das reuniões de equipe ou de processos de qualificação, com o risco de favorecer, assim, a negação do seu lugar de profissional da saúde. Ao admitir, como disposto na PNAB 2017, a composição de equipes com profissionais com carga horaria variável, até mesmo de apenas dez horas de atuação, acentua-se o risco de perda de coesão e de maior fragmentação do cuidado, com efeitos para a inserção do ACS e o que se espera do seu trabalho. Arrisca-se também promover uma posição mais passiva, na qual o ACS perderia autonomia e capacidade de articular propostas com a equipe. 
Fonseca, A. F.; Morosini, M. V.

Quadro $3^{2}$ - Documentos normativos da Atenção Básica e relações com o trabalho do ACS

\begin{tabular}{|c|c|c|c|c|}
\hline PNAB 2017 & CASAPS & Previne Brasil & ADAPS & Comentários \\
\hline $\begin{array}{l}\text { Não estabelece número mínimo de } \\
\text { ACS por equipe de ESF. } \\
\text { Prevê outras modalidades de } \\
\text { equipe, além da eSF, próximas ao } \\
\text { que reconhecemos como AB } \\
\text { tradicional, em que a presença do } \\
\text { ACS é facultativa. Associa às } \\
\text { equipes AB possibilidades de novos } \\
\text { arranjos de carga horária, } \\
\text { permitindo profissionais com } \\
\text { apenas dez horas na equipe. } \\
\text { Muda as atribuições dos ACS, com } \\
\text { definição de atribuições comuns } \\
\text { com os ACE e acréscimo de } \\
\text { atribuições de caráter clínico. } \\
\text { Estabelece dois padrões de } \\
\text { organização dos serviços, essencial } \\
\text { e ampliado, contribuindo para a } \\
\text { segmentação do cuidado, a partir } \\
\text { da oferta. Nesse sentido, amplia o } \\
\text { espaço para a concepção seletiva } \\
\text { da APS na AB, com implicações } \\
\text { para o trabalho do ACS (maior ou } \\
\text { menor complexidade). } \\
\text { Afasta-se também da ideia de } \\
\text { direito universal. }\end{array}$ & $\begin{array}{l}\text { O ACS é referido somente uma vez no } \\
\text { texto da CaSAPS, associado ao cuidado no } \\
\text { puerpério. } \\
\text { A visita domiciliar está associada somente } \\
\text { aos usuários restritos ao domicílio, como } \\
\text { recém-nascidos e acamados. } \\
\text { Não há referência à ideia de participação } \\
\text { popular, expressão que sequer aparece na } \\
\text { CaSAPS. } \\
\text { Denota: esvaziamento do enfoque da } \\
\text { territorialização e enfraquecimento da } \\
\text { noção de comunidade; perda do horizonte } \\
\text { de construção de relações entre as equipes } \\
\text { e as pessoas das diferentes comunidades; } \\
\text { Ao preterir a participação popular, diretriz } \\
\text { histórica do SUS e da ESF, em relação } \\
\text { direta com o trabalho do ACS, a CaSAPS } \\
\text { deixa de afirmar os usuários como sujeitos } \\
\text { do processo de organização da atenção, } \\
\text { condição para a realização da } \\
\text { integralidade. } \\
\text { A carteira de serviços é fundamental para a } \\
\text { precificação, necessária ao processo de } \\
\text { contratação de serviços ao setor privado. } \\
\text { Suas orientações convergem para a ideia } \\
\text { de segmentação do cuidado e } \\
\text { estabelecimento de mínimos, típicos da } \\
\text { APS seletiva. }\end{array}$ & $\begin{array}{l}\text { O Previne Brasil extingue o PAB fixo- } \\
\text { única transferência } \\
\text { intergovernamental em saúde com } \\
\text { base populacional (perda do } \\
\text { financiamento universal da AB). } \\
\text { Adota a capitação baseada na pessoa } \\
\text { cadastrada, mais um instrumento } \\
\text { para a precificação, e o pagamento } \\
\text { por desempenho, centrado em } \\
\text { poucos indicadores de base clínica. } \\
\text { Enfatiza a 'pessoa assistida', } \\
\text { desconsiderando o processo social e } \\
\text { político de produção das } \\
\text { vulnerabilidades. } \\
\text { Denota tendência a tornar menos } \\
\text { visíveis os problemas territoriais e a } \\
\text { desmobilizar ações do campo da } \\
\text { saúde que transcendam a } \\
\text { perspectiva biomédica, como as que } \\
\text { conferem complexidade ao trabalho } \\
\text { do ACS. }\end{array}$ & $\begin{array}{l}\text { Permite importante } \\
\text { transferência de } \\
\text { responsabilidades gestoras } \\
\text { do Ministério da Saúde para a } \\
\text { ADAPS. } \\
\text { Configura um novo e mais } \\
\text { abrangente instrumento para } \\
\text { a expansão do setor privado } \\
\text { no SUS, permitindo a atuação } \\
\text { direta das empresas privadas } \\
\text { de saúde na assistência na } \\
\text { AB, com acesso a fontes } \\
\text { públicas, estáveis e } \\
\text { volumosas de financiamento. } \\
\text { Denota uma posição mais } \\
\text { ativa e radicalizadora do } \\
\text { gestor federal na formulação } \\
\text { de políticas que estabelecem } \\
\text { uma indistinção entre o } \\
\text { público e o privado em } \\
\text { relação ao SUS. } \\
\text { Indaga-se qual papel o ACS } \\
\text { teria numa APS privatizada? }\end{array}$ & $\begin{array}{l}\text { A apreensão da noção de território está } \\
\text { sendo cada vez mais simplificada, } \\
\text { aproximando-se à ideia de local. } \\
\text { Na PNAB as particularidades do território são } \\
\text { utilizadas para justificar padrões } \\
\text { diferenciados de organização dos serviços da } \\
\text { AB, afetando a presença dos ACS. } \\
\text { O distanciamento em relação à } \\
\text { universalidade como princípio é percebido } \\
\text { na PNAB } 2017 \text { e explicitado pelo Previne } \\
\text { Brasil, ao romper com o PAB fixo. } \\
\text { O afastamento da perspectiva do território, } \\
\text { da orientação comunitária e da participação } \\
\text { popular na CaSAPS, associadas ao } \\
\text { descompromisso com a universalização da } \\
\text { AB, afetam diretamente o sentido e o escopo } \\
\text { do trabalho dos ACS. } \\
\text { A lógica individualizante e biomédica do } \\
\text { cuidado em saúde presentes na CaSAPS e no } \\
\text { Previne Brasil somada às atribuições de } \\
\text { caráter clínico colocadas para os ACS na } \\
\text { PNAB } 2017 \text { indicam um esvaziamento do } \\
\text { perfil social do seu trabalho. } \\
\text { A direção privatizante dos documentos } \\
\text { normativos analisados denota uma } \\
\text { incompatibilidade com a perspectiva da } \\
\text { determinação social do processo saúde- } \\
\text { doença sobre a qual se estrutura o trabalho } \\
\text { do ACS na ESF, orientada pela APS integral. }\end{array}$ \\
\hline
\end{tabular}

Fonte: produção das autoras

Quadro produzido a partir das análises desenvolvidas em Morosini, Fonseca e Baptista, 2020 


\section{DESDOBRAMENTOS}

\section{CONTEXTO DA COVID-19:}

POTENCIAL E RISCOS SOBRE OS

\section{QUAIS REFLETIR}

O curso dessas mudanças é atravessado pela pandemia de COVID-19. Ficaram expostas duas faces marcantes da inserção desse trabalhador na APS: sua vulnerabilidade e relevância para o SUS.

De um lado, evidenciou-se a insegurança da sua posição. O não reconhecimento do ACS como profissional da saúde tornou-se evidente na desigualdade de acesso a equipamentos de proteção individual, um dos temas mais recorrentes nos relatos desses trabalhadores sobre as condições em que atuaram na pandemia. Outros elementos captados nos relatos e estudos sobre esse contexto e que refletem a debilidade de sua posição como profissional da saúde foram a dificuldade para a realização de testes diagnósticos nas situações de suspeita de contaminação, a ausência de estratégias visando à sua qualificação para atuação na pandemia e o não cumprimento de direitos, como o afastamento remunerado do serviço. (Lotta et al, 2020; Nogueira et al, 2020). A confirmação dos ACS como trabalhadores da saúde é objeto do Projeto de lei 1802/2019, aprovado em abril de 2021 pela Câmara dos Deputados e encaminhado ao Senado. Sua justificativa é "dirimir questionamentos que remanescem em Estados e Municípios acerca da natureza da atuação profissional desempenhada pelos Agentes de Combate às Endemias e Agentes Comunitários de Saúde, notadamente vinculada à saúde".

De outro lado, o desenvolvimento da pandemia expôs a indissociabilidade entre as dimensões biológica, cultural e social da COVID-19. Emergem na cena pública situações reais que concretizam a urgência de intervir nessas três dimensões. Sendo o ACS o profissional cujo trabalho remete diretamente a essa múltipla determinação, as ações com maior probabilidade de obter resultados favoráveis recuperam as razões para a aposta feita no trabalho do ACS na ESF.
As dificuldades para a implantação das medidas de distanciamento social, a difusão de desinformação (fakenews), a hesitação vacinal, o agravamento das condições sociais - aumento do desemprego, crescimento da insegurança nutricional, retorno da fome e intensificação da violência doméstica - são algumas circunstâncias agudizadas pela pandemia que acarretam problemas com os quais o ACS já lidava cotidianamente. Contudo, essa vivência e seu pertencimento à parcela da população mais exposta aos riscos e danos associados à pandemia o sensibilizam, mas não são suficientes para habilitá-lo para uma atuação qualificada.

Nesse contexto, cabe aos defensores da APS integral posicionar-se politicamente, planejar ações estratégicas para consolidar a presença do ACS na ESF e apoiar os mecanismos que contribuam para a sua integração à equipe de saúde. Implica a garantia de sua formação profissional técnica, de educação permanente e a promoção de formas seguras e dignas de vinculação ao trabalho. Requer a renovação do compromisso com o trabalho em rede, tanto no âmbito da atenção à saúde como intersetorialmente e com os movimentos sociais.

O inventário dos desafios colocados para a APS no que diz respeito aos ACS leva-nos ao exercício de antecipar possíveis desdobramentos de tendências produzidas no cenário atual. Um legado indiscutível do contexto pandêmico foi a expansão do trabalho em saúde por meio de tecnologias digitais de informação e comunicação (TDIC). A continuidade do trabalho, também na APS, esteve ancorada na incorporação de dispositivos de comunicação remota. Difundiu-se o uso de aparelhos móveis, como celulares e tablets, para a realização, dentre outros, do trabalho que não podia ser feito presencialmente, para alcançar usuários que não podiam comparecer aos serviços e para organizar fluxos de atendimento. Em muitas situações, isso se fez com a utilização de aparelhos e linhas, ou redes, dos próprios trabalhadores (Rede APS, 2021). Também se utilizaram plataformas e acionaram recursos digitais para a realização de atividades de 
caráter informativo e formativo, muitas vezes, articulando instituições e organizações do campo da saúde e da educação.

O uso emergencial dessa forma de comunicação tem impulsionado um processo mais abrangente de transformação do trabalho em saúde, caracterizado pela incorporação do teleatendimento ${ }^{3}$. Ante esse fenômeno, consideramos necessário ultrapassar o dualismo segundo o qual a tecnologia é má ou boa (Liu, 2021) e nos concentrar em seus modos de uso, atentos ao fato que sua inserção no processo de trabalho não escapa às contradições e aos tensionamentos que atravessam os contextos sociais, permeados por interesses econômicos, além das características, no caso em pauta, da APS brasileira.

A argumentação em favor da incorporação das atividades 'tele' na APS tem se apresentado de duas formas principais. Na primeira, defende-se o seu caráter estratégico, porém complementar, em relação ao conjunto de atividades presenciais. Experiências que afirmam e efetivam essa complementariedade têm sido implementadas, mostrando resultados positivos convergentes com os atributos da APS integral (Rede APS, 2021). Na segunda, atribui-se à telessaude a capacidade para reorganizar o sistema de saúde, ocupando um lugar estruturante (Silva et al, 2021 e Katz et al, 2020). Percebe-se uma ideia de equivalência com o trabalho que se realiza por meio da interação presencial. A defesa dessa equivalência implica admitir que não há prejuízo significativo na supressão do encontro real entre os sujeitos do cuidado ou que esse prejuízo se justifica frente aos ganhos da viabilização do acesso ao cuidado, ainda que virtual, da redução dos custos e da otimização do fluxo de informações e pessoas na rede de atenção.

Cabem aqui algumas reflexões críticas sobre possíveis repercussões que a generalização desse modo de praticar o cuidado pode trazer

${ }^{3}$ Estamos incluindo na noção de teleatendimento as práticas relacionadas à telemedicina, teleconsulta, teleassistência, ou seja, as atividades de cuidado entre para a APS e, em particular, para o trabalho do ACS.

Distinguimos duas condições para a expansão irrestrita dessa modalidade de atenção, e ambas indicam perdas frente à perspectiva da APS integral. A primeira é destituir de importância a territorialização, entendida como modo de organização dos serviços e das práticas de saúde, com centralidade no território e responsabilidade sanitária, que requer a compreensão dos processos que condicionam a vida e as relações sociais num espaço determinado, considerando as especificidades das situações ambientais, populacionais e as necessidades de saúde (Gondim e Monken, 2018). Essa é uma dimensão que requer presença contínua e circulação no território.

Outra condição é substituir a 'atenção à saúde' por 'assistência individual' - atualizada para 'atenção centrada na pessoa' -, modelo de práticas que tem maior compatibilidade com o formato 'tele' e que vinha perdendo espaço na caracterização do cuidado em saúde mediante a luta histórica em torno da concepção biopsicossocial do adoecimento e da perspectiva da integralidade. Entendemos que inflexões trazidas pelas novas normativas, aqui já abordadas, convergem para que se estabeleçam essas condições.

Embora não seja possível antecipar todas as consequências, é necessário atentar para o risco de se acentuar a invisibilidade das dinâmicas sociais na produção do adoecimento e de se limitar o foco da atenção, enfatizando aspectos clínicos que reforcem o modelo de queixaconduta que a ESF busca superar. Não é à toa que a oportunidade para o teleatendimento ampliar seu espaço de atuação e lograr resultados satisfatórios seja o contexto de uma doença. A urgência e a gravidade da COVID-19 pressionaram os serviços pela oferta de atendimentos para o diagnóstico rápido, o monitoramento clínico e o tratamento oportuno, numa perspectiva estritamente biomédica. $\mathrm{O}$ fato de o encontro presencial ter

sujeitos (profissional e usuário) mediadas pelas tecnologias de comunicação. 
se tornado fonte de risco e o distanciamento social, necessário, compôs as circunstâncias nas quais as virtudes do teleatendimento se destacaram.

Diante da tarefa de indicar possíveis desdobramentos caso o teleatendimento se generalize e ganhe centralidade na organização do cuidado na APS, endereçamos duas preocupações acerca do trabalho do ACS. A primeira diz respeito a mais uma vertente da instrumentalização de suas atividades, pela subordinação da finalidade e do conteúdo do seu trabalho, a uma perspectiva utilitarista segundo a qual ele possa ser acionado para cumprir, sob demanda, tarefas geradas a partir de uma abordagem limitada da clínica e da vigilância, e simplificação do processo saúdedoença. Numa perspectiva ainda mais reducionista e extrema, num cenário de poucos ACS nas equipes, seu papel pode ser o de viabilizar o acesso; não mais ao serviço, mas ao equipamento necessário ao teleatendimento. Desse modo, a face do trabalho do ACS em que se destaca o verbo 'entregar' - agendamentos, insumos de higiene, medicamentos - ganharia novos objetos. (Fonseca e Mendonça, 2015).

A produção de informações, hoje importante no conjunto de atividades realizadas pelo ACS, tende a ganhar relevância ainda maior no contexto digital. Aí reside a segunda preocupação, pois na ausência de contextos favoráveis de encontro, essa produção pode ficar reduzida à coleta de dados. Indaga-se, então, em quais espaços as informações seriam compartilhadas em equipe, alimentando a construção de pontos de vista sobre as melhores formas de produzir atenção à saúde? Caso o teleatendimento se torne prática corrente também para o ACS, quais sentidos sustentariam a visita domiciliar, atividade estruturante do seu trabalho? A visita domiciliar é compreendida aqui como espaço de encontro, regular e frequente, contexto de interação subjetiva, ancorada no vínculo.

Em outros setores, a hipertrofia do trabalho digital tem acentuado a precarização do trabalho, conforme indicam autores como Antunes (2021) e Grohmann (2021), ainda que seus efeitos sejam diferentes conforme o ramo de atividades e as funções exercidas. Representa um importante nicho de mercado tecnológico e de produção e mercantilização de dados que avançam sobre o setor público, acompanhados da capilarização da normatividade e dos interesses do setor privado. No que tange à APS, não se pode esquecer a histórica disputa entre perspectivas que compreendem a saúde como direito universal e responsabilidade do Estado ou que a formulam como mercadoria em que a noção de equidade é suplantada pela diretriz custo-efetividade. A análise do trabalho do ACS, trabalhador exclusivo da APS, não pode prescindir da compreensão do quadro geral dessas disputas e das tendências que se materializam em cada contexto. Tal disputa encontra mecanismos frequentes de atualização, criando novas oportunidades, redefinindo relações e alternando focos de interesse e pressão, como demonstra a consulta pública lançada em maio de 2021 (Brasil, 2021) sobre a Política Nacional de Saúde Suplementar (PNSS-COVID-19).

Nesse sentido, recomendações dirigidas para compor uma agenda de fortalecimento do trabalho do ACS devem promover e incorporar resultados de pesquisa e dialogar com o plano mais geral de formulação da política, entendendo suas repercussões sobre o plano mais específico da atuação dos ACS.

\section{INDICAÇÕES PARA A AÇÃO: PRINCÍPIOS DO SUS E A APS INTEGRAL COMO FUNDAMENTO}

A reflexão e a proposição sobre o trabalho do ACS partem da compreensão que este não é um trabalhador isolado. Ele integra uma equipe multiprofissional e, embora tenha atribuições e responsabilidades específicas, elas só se realizam na interação com as atribuições e as responsabilidades dos demais profissionais, dos serviços e da rede que compõe o SUS, condição para que resultem em ampliação do acesso e qualidade da atenção. Tendo em vista essa compreensão, propomos uma pauta de 
prioridades que combinam pesquisa, posicionamentos ético-políticos e iniciativas de gestão que possam consolidar a presença, recuperar o sentido e qualificar o escopo de ações dos ACS, tendo a APS integral como fundamento e os princípios do SUS como norte.

Afirmar o ACS como um trabalhador da saúde, portador de direitos e protagonista do cuidado promovido na APS.

Investigar novas configurações das equipes de Atenção Básica e de Estratégia Saúde da Família, no sentido de caracterizar alterações quanto a presença e número de ACS nas equipes; a relação com a população sob sua responsabilidade, mapeando seu escopo de práticas e consolidando análises sobre implicações dessas mudanças para o sentido do trabalho e a sua interação com a perspectiva da APS integral

Sistematizar experiências de participação do ACS na promoção à saúde, com particular atenção àquelas postas em curso no contexto da COVID-19, caracterizando eixos de atuação que contribuem para o fortalecimento da APS integral, articulada interinstitucional e intersetorialmente.

Considerar, no contexto pós Covid-19, o papel que os ACS podem desempenhar no acompanhamento de pessoas que apresentem sequelas decorrentes do adoecimento, cujo cuidado integral pode requerer articulações com outros serviços.

Fortalecer o papel do ACS na promoção da imunização. Reconhecer seu potencial para combater o fenômeno da hesitação vacinal de modo contínuo, dadas as suas possibilidades de compreender melhor as razões e os sentidos dessa hesitação, assim como de propor estratégias mais efetivas para a sua superação.

Valorizar as ações desempenhadas pelos ACS para a promoção da participação popular e a ativação de redes de apoio local.

Formular propostas de avaliação do trabalho do ACS que assumam a continuidade da atenção, o enfoque comunitário e a integralidade como principais referências de qualidade e contemplem a complexidade das ações de educação em saúde.

Organizar estratégias de resistência sistemática às normatizações dirigidas à $A B$, de modo $a$ recompor a centralidade da ESF, a ênfase na orientação comunitária, a compreensão da determinação social do processo saúde-doença, a perspectiva do cuidado territorializado e a diretriz da participação popular, eixos fundamentais da APS integral e do trabalho do ACS.

Recuperar a definição de parâmetros quantitativos para a presença dos ACS nas equipes de saúde da família, orientados pela perspectiva da universalização e integralidade da atenção à saúde.

Manter e priorizar a presença e atuação dos ACS no território, considerando o seu papel para a construção e manutenção da perspectiva comunitária na APS.

Rever a organização do processo de trabalho na ESF, de modo a diminuir o impacto das atividades burocráticas sobre o cotidiano de trabalho dos ACS, preservando a centralidade do trabalho baseado na interação pessoal.

Rever o escopo de práticas dos ACS, garantindo a articulação entre as atribuições de caráter clínico e a centralidade do seu papel de educador em saúde na interface entre serviço e território.

Promover a formação técnica dos ACS como política pública, coerente com a complexidade requerida pelo seu trabalho e compromissada com a sua profissionalização, não somente com a sua instrumentalização para o trabalho.

Instituir processos regulares de educação permanente em saúde e meios de garantir a participação equânime.

Manter permanente interação com 0 movimento organizado dos trabalhadores ACS, de modo a garantir o debate e a articulação de propostas participativas que contemplem tanto os diretos dos trabalhadores como os atributos da APS integral e os princípios do SUS. 


\section{REFERÊNCIAS}

ANTUNES, R. Capitalismo de plataforma e desantropomorfização do trabalho. In: GROHMANN, R. Os laboratórios do trabalho digital: entrevistas. São Paulo: Boitempo, 2021, p.33-38.

BRASIL. Ministério da Saúde. Portaria no 2.436, de 21 de setembro de 2017. Aprova a Política Nacional de Atenção Básica, estabelecendo a revisão de diretrizes para a organização da Atenção Básica, no âmbito do Sistema Único de Saúde (SUS). Diário Oficial da União 2017; 22 set.

BRASIL. Medida Provisória no 890, de 1 de agosto de 2019. Institui o Programa Médicos pelo Brasil. Diário Oficial da União 2019; 1ㅇago.

BRASIL. Ministério da Saúde. Portaria no 2.979, de 12 de novembro de 2019. Institui o Programa Previne Brasil. Diário Oficial da União 2019; 13 nov.

BRASIL. Ministério da Saúde. Consulta Pública da Política Nacional de Saúde Suplementar para o Enfrentamento da Covid-19. Disponível em: <https://www.gov.br/participamaisbrasil/pnss-covid-19> Acesso em: 8 ago. 2021.

BRASIL. Ministério da Saúde. Carteira de Serviços da Atenção Primária à Saúde (CaSAPS). Versão profissionais de saúde e gestores - completa. Brasília: 2020. http://189.28.128.100/dab/docs/portaldab/documentos/casaps_versao_profissionais_saude_gestores_ completa.pdf (acessado em 15/Fev/2020).

FONSECA, A. F.; MENDONÇA, M. H. M. Parcelarização e simplificação do trabalho o Agente Comunitário de Saúde. Rev. Lat. Estudios del Trab., 2015, 20:29-57. https://www.arca.fiocruz.br/handle/icict/25376 (acessado em 2/ago/2021).

GIOVANELLA, Lígia et al. Médicos pelo Brasil: caminho para a privatização da atenção primária à saúde no Sistema Único de Saúde?. Cad. Saúde Pública, 35:10 e00178619 https://doi.org/10.1590/0102$\underline{311 \times 00178619}$ (acessado em 26/jul/2021)

GONDIM G. M. M.; MONKEN, M. O uso do território na atenção primária à saúde. In: MENDONÇA, M. H. M.; MATTA, G. C.; GONDIM, R.; GIOVANELLA, L. (organizadores). Atenção Primária à Saúde no Brasil: conceitos, prática e pesquisa. Rio de Janeiro: Editora Fiocruz; 2018. p. 143-75.

GROHMANN, R. Introdução. Trabalho em plataformas é laboratório de luta de classes. In: GROHMANN, R. Os laboratórios do trabalho digital: entrevistas. São Paulo: Boitempo, 2021, p.13-23.

HIRATA H. Subjetividade e sexualidade no trabalho de cuidado. Cad. Pagu, 46:151-63. https://periodicos.sbu.unicamp.br/ojs/index.php/cadpagu/article/view/8645399 (acessado em 12/jul/2021)

KATZ, N. et al. Acesso e regulação ao cuidado especializado no Rio Grande do Sul: a estratégia RegulaSUS do TelessaúdeRS-UFRGS. Ciênc Saúde Coletiva. 2020, 25:1389-1 < https://doi.org/10.1590/141381232020254.28942019> (acessado em 10/ago/2021)

LIU, W. Abolir o Vale do Silício e Organizar os Trabalhadores. In: GROHMANN, R. Os laboratórios do trabalho digital: entrevistas. São Paulo: Boitempo, 2021, p.193-195.

LOTTA, G.; FERNANDEZ, M.; CORRÊA, M. The vulnerabilities of the Brazilian health workforce during health emergencies: Analysing personal feelings, access to resources and work dynamics during the COVID-19 pandemic. Int J Health Plann Manage. 2021 36(S1):42-57. DOI: 10.1002/hpm.3117

MOROSINI, M. V. G. C. Transformações no trabalho dos agentes comunitários de saúde nos anos 19902016: a precarização para além dos vínculos [tese de doutorado]. Universidade do Estado do Rio de Janeiro. Centro de Educação e Humanidades, 2018. < https://www.arca.fiocruz.br/handle/icict/33269>. (acessado em 10/ago/2021)

MOROSINI, M. V. G. C.; FONSECA, A. F. Revisão da Política Nacional de Atenção Básica numa hora dessas? Cad. Saúde Pública, 2017; v. 33 n. 1, p. 1-4. 
MOROSINI, M. V. G. C.; FONSECA, A. F.; BAPTISTA, T. W. F. Previne Brasil, Agência de Desenvolvimento da Atenção Primária e Carteira de Serviços: radicalização da política de privatização da atenção básica? Cad. Saúde Pública, 36, 9: 1-20, 2020.<https://www.arca.fiocruz.br/handle/icict/43663>. (acessado em 10/ago/2021)

NOGUEIRA, M. L. et al. 1o. Boletim da Pesquisa "Monitoramento da saúde dos ACS em tempos de Covid19. Rio de Janeiro: 72 p. https://www.arca.fiocruz.br/handle/icict/42709 (acessado em 12/jul/ 2021)

Rede de Pesquisa em Atenção Primária à Saúde da ABRASCO. A APS não pode parar! continuidade do cuidado durante e após a pandemia. Seminário 2021, 10 ago 2021. <https://www.youtube.com/watch?v=|Yq3gbnUgpM>

RIQUINHO, D. L. et al. O cotidiano de trabalho do agente comunitário de saúde: entre a dificuldade e a potência. Trab. Educ. saúde, 2018, 16:163-182. <https://doi.org/10.1590/1981-7746-sol00086>. (acessado 4/ag0/2021)

SANTOS, L. T.; SOUZA, F. O.; FREITAS, P. S. P. Rev. Efeitos do trabalho sobre o adoecimento entre agentes comunitários de saúde - uma revisão de literatura. Aten. Saúde, jul./set., 2019, 17:105-113.

SILVA, R. S. et al. O Papel da Telessaúde na Pandemia Covid-19: Uma Experiência Brasileira. Ciec. Saúde Coletiva, 2021, 26: 2149-2157. < https://doi.org/10.1590/1413-81232021266.39662020> (acessado 4/ago/2021 